\title{
Dibujo arqueológico e ilustración histórica: una profesión apasionante al servicio de la sociedad
}

El dibujo arqueológico y la ilustración histórica son disciplinas muy relacionadas entre sí que constituyen una parte fundamental de la ciencia arqueológica. Sus objetivos son documentar y proponer hipótesis de reconstrucción del pasado a la sociedad. En el siglo XXI se ha producido una auténtica revolución de la mano de las herramientas digitales, como la fotogrametría y el diseño digital o las técnicas de virtualización del patrimonio. Pero son muchos los retos: debemos profundizar en una formación superior reglada y más completa, en una normalización del lenguaje del nuevo dibujo arqueológico y en iniciativas que vayan en la línea de reforzar y promocionar la figura del dibujante o ilustrador de arqueología.

Iñaki Diéguez Uribeondo | vicepresidente de ADARQ (Asociación Nacional de Dibujantes e Ilustradores de Arqueología)

URL de la contribución <http://www.iaph.es/revistaph/index.php/revistaph/article/view/4367>

Desde sus inicios como ciencia e incluso con anterioridad, la arqueología ha necesitado acompañar de imágenes su relato escrito para explicarlo y compartirlo con la sociedad.

En nuestra profesión existen dos líneas fundamentales de trabajo: el dibujo arqueológico y la ilustración histórica. Como sabemos, el dibujo arqueológico consiste en documentar gráficamente las estructuras y materiales de una intervención arqueológica siguiendo unos códigos normalizados y tras una necesaria labor de análisis y selección previa. La ilustración histórica va un paso más allá y utiliza esos datos para reconstruir o recrear el pasado, en muchas ocasiones generando una imagen que nos sumerge de lleno en la antigüedad, como si fuese una ventana real abierta a épocas pasadas. Nuestra profesión nos obliga a trabajar habitualmente en esos dos planos, reflejando evidencias concretas o utilizando dichos datos para proponer hipótesis que muchas veces son tan solo aproximaciones, sujetas a una revisión constante con el paso del tiempo y el avance de nuestra disciplina.

En ambos casos nuestra labor es fundamental para la difusión de la ciencia y el retorno del conocimiento al público. Nuestro papel ante la sociedad es muy importante; sin embargo, esta relevancia contrasta con la peculiar, heterogénea y muy a menudo incompleta for-
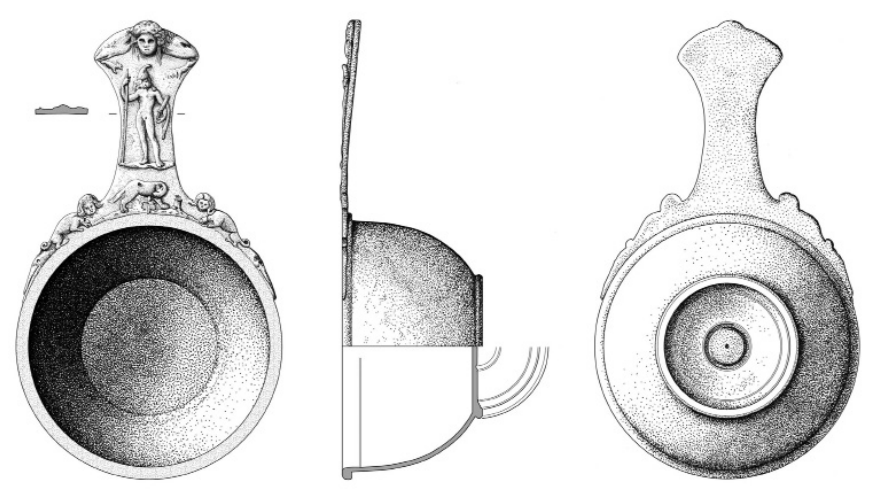

Un ejemplo de dibujo de material arqueológico: trulla o cacito ritual romano, procedente de las excavaciones de la antigua Pompaelo (Pamplona, Navarra) (2010) | todos los dibujos e ilustraciones son de Iñaki Diéguez Uribeondo

mación que habitualmente se ofrece al profesional del dibujo arqueológico. Hasta hace pocos años (y aún en la actualidad) la persona encargada de dibujar los materiales arqueológicos de una excavación solía ser un delineante o más habitualmente un arqueólogo "con buena mano", es decir, con ciertas habilidades de dibujo. Esto ocurría también en el registro de campo cuyas técnicas de medición y registro no habían variado sustancialmente en décadas y que con frecuencia realizaban los propios arqueólogos, o bien topógrafos especializados. En el caso de la ilustración histórica la heterogeneidad 
era más evidente; a los arqueólogos, arquitectos y delineantes se unían artistas y licenciados en Bellas Artes, que eran quienes solían encargarse de este tipo de trabajo desde las primeras publicaciones científicas del siglo XIX y a lo largo del siglo XX (veánse en este sentido las obras de Proskouriakoff, 1946 o Augusta, 1964).

Una de las principales razones de que el perfil profesional del dibujante o ilustrador haya sido tan variado es la fragmentada, incompleta y escasa oferta formativa que existía hasta hace poco tiempo en nuestro país y que, de hecho, aún sigue existiendo en muchos ámbitos. Hasta hace pocos años y aún en la actualidad, nuestra disciplina se aprendía de forma autodidacta y muy a menudo una vez finalizados los estudios universitarios, ya que no en todas las universidades existe como materia optativa y menos aún obligatoria. Sin ir más lejos, hasta hace bien poco resultaba una labor complicada localizar un manual que explicara de manera completa y clara los fundamentos del dibujo arqueológico en castellano. Dichas publicaciones existían como publicaciones fragmentadas y casi artesanales de diversas universidades o centros de estudios de nuestro país y no constituían un libro de cabecera completo para los estudiantes. Los profesionales del dibujo hemos tenido que basarnos en las publicaciones extranjeras especializadas que desde el último cuarto del siglo $X X$ se habían preocupado por intentar normalizar nuestra disciplina (BRODRIBB, 1971; ARCELIN, 1979; DILON, 1981; ADKINS, 1989; HAWKER, 2001; PENNACCHIONI, 2004). Es en los últimos años cuando esta situación ha comenzado a cambiar, con las publicaciones de Bagot (2005), De Luis (2010) o Mas (2016), si bien aún estamos lejos de contar con un manual completo y actualizado que abarque todas las aplicaciones del dibujo arqueológico entendido como disciplina total, y lo más parecido sigue siendo el ya citado manual de Adkins (1989).

Sin embargo, hoy día el panorama ha mejorado de manera notable: el perfil del dibujante e ilustrador ha cambiado, especialmente en lo relativo a su formación. Muchos arqueólogos se han adaptado a los nuevos tiempos y se han reciclado adquiriendo conocimientos de fotogrametría, técnicas de diseño e ilustración digital. También han surgido nuevos perfiles profesionales muy especializados, como el de los especialistas en registro fotogramétrico y virtualización del patrimonio. Asimismo, la nueva generación de estudiantes e ilustradores demandan una formación cada vez más especializada y completa. Se están generalizando diferentes cursos de formación online, talleres prácticos y cursos específicos promovidos por universidades, museos y otras instituciones. Se tiende a la creación de una mayor oferta académica reglada tanto para el dibujo arqueológico como para la ilustración histórica, si bien se trata de un proceso en el que (especialmente en ilustración) se están dando los primeros pasos. Cabe destacar en este sentido iniciativas recientes como el Postgrado de llustración Científica de la Universidad del País Vasco (2017) o el Curso de Especialización en Ilustración Histórico-Arqueológica, de Patrimonio Virtual y la Universidad de Alicante (2018)2. Ya se están preparando otras iniciativas promovidas por otras universidades como la Fundación Universidad de La Rioja y EADE Universidad en Málaga, por ejemplo.

Asimismo, destacan acciones que tienen como objetivo reforzar la figura del profesional de nuestra disciplina, como ha sido la creación en 2015 de la Asociación Nacional de Dibujantes e llustradores de Arqueología (ADARQ) y de su revista científica Schema (CARMONA, 2017; 2018), especializada en artículos sobre dibujo arqueológico e ilustración histórica, y que fue reconocida como un hito en nuestra disciplina en la exposición que se celebró en el Museo Arqueológico Nacional con

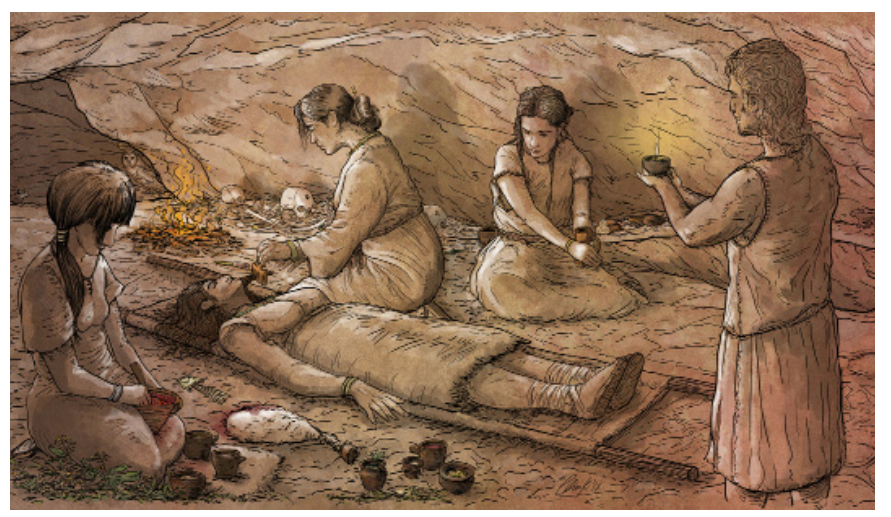

La ilustración histórica como ventana al pasado: recreación de un ritual funerario de época talayótica en el interior de la Cova des Carritx (Menorca) hacia el año 1100-800 a.C (2018) | ilustración según las indicaciones de Elena Sintes y Majo León. Museu de Ciutadella, Menorca 


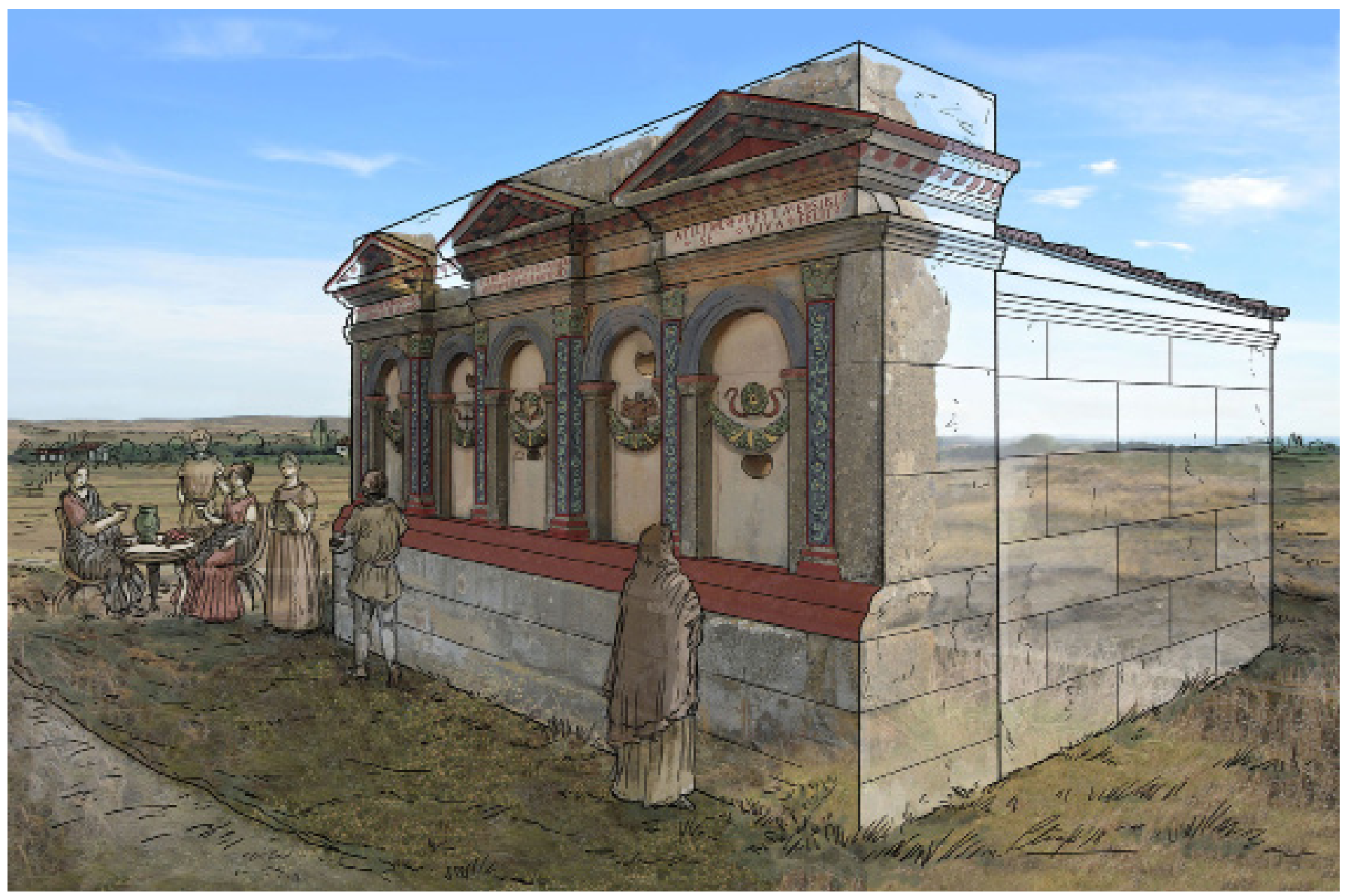

Fusión de técnicas tradicionales, digitales y fotografía: reconstrucción hipotética del acotado funerario de los Atilios (s. I d.C) cerca de Sádaba (Zaragoza) (2018) | ilustración según las indicaciones de Javier Andreu Pintado, y en base a la restitución virtual realizada por Pablo Serrano Basterra. Fundación Los BañalesGobierno de Aragón

motivo de la conmemoración de los 150 años de la disciplina arqueológica en España (RUIZ, 2018).

No es fácil saber de manera exacta cómo será nuestra profesión en el futuro. En lo que se refiere al dibujo arqueológico, la revolución digital nos ha obligado a cuestionarnos las técnicas utilizadas hasta ahora para medir, dibujar y difundir. Estamos en proceso de crear un nuevo dibujo arqueológico y ésta es una tarea aún pendiente. Queda por resolver la forma de fusionar las técnicas digitales con el lenguaje tradicional y relativamente normalizado del dibujo arqueológico.

En el campo de la ilustración histórica los avances más claros han sido en el aspecto técnico, lo que ha tenido como consecuencia una reducción notable del uso de las técnicas tradicionales. Sin embargo, no tenemos que pensar que estas técnicas ya no son adecuadas; queda a elección de cada ilustrador el uso de una técnica u otra, y del modo en que las combine, pues todas ellas son igualmente válidas. La ilustración histórica sigue suponiendo una herramienta de primer orden para la difusión del patrimonio especialmente en un mundo presidido por el consumo masivo de imágenes, y ha sabido adaptarse perfectamente a los formatos digitales desde la aparición de las primeras apps y soportes interactivos (véase por ejemplo SEVILLANO, 2013) sin perder presencia en los contextos tradicionales, como museos, yacimientos arqueológicos o exposiciones, donde se conjuga a la perfección con las tecnologías actuales. 


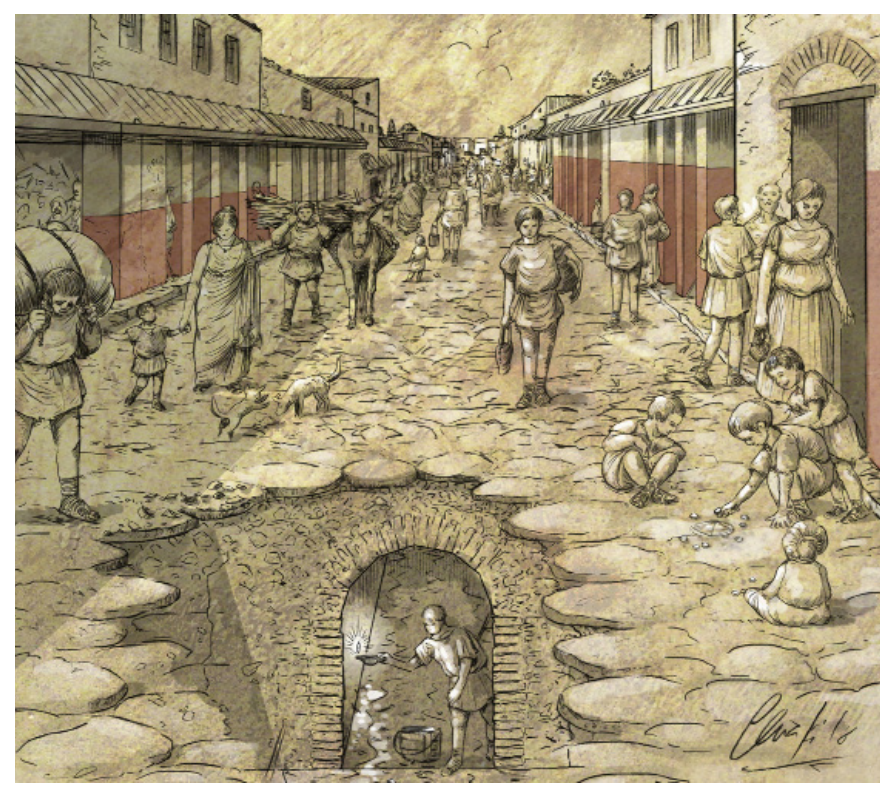

La ilustración histórica al servicio del público: reconstrucción del Cardo Maximo y de la cloaca principal de la ciudad romana de Itálica en Época Adrianea (s. II d.C.) (2018) | ilustración según las indicaciones de Daniel González Acuña. Conjunto Arqueológico de Itálica, Junta de Andalucía

Para terminar, hemos de decir que las imágenes siempre serán necesarias para difundir nuestro patrimonio. Podrá variar la técnica y la forma elegidas para hacerlo, pero sin duda el dibujo y la ilustración seguirán siendo un elemento fundamental para la difusión de la arqueología a toda la sociedad pues concretan y sintetizan gran cantidad de información de manera muy accesible para un gran porcentaje de la sociedad.

\section{NOTAS}

1. Iñaki Diéguez Uribeondo es arqueólogo e ilustrador, y socio co-fundador de ADARQ (en 2015). Tiene una web donde muestra su trabajo: <www.idu-ilustracion.com>

2. El autor es profesor en ambos postgrados.

\section{BIBLIOGRAFÍA}

- ARCELIN, P.; RIGOIR, Y. (1979) Normalisation du dessin en ceramologie. Documents $D^{\prime}$ Archeologie Meridionale, n. ${ }^{\circ}$ spécial 1, 1979

- ADKINS, R. (1989) Archaeological Illustration. Cambridge: Cambridge Manuals in Archaeology, 1989

- AUgusta, J.; BURIAN, Z. (1964) Los Hombres Prehistóricos. México: Queromón editores, 1964

- BAgot, F. (2005) El dibujo arqueológico. La cerámica. Normas para la representación de las formas y decoraciones de las vasijas. Lima: CEMCA-IFEA, 2005

- BRODRIBB, C. (1971) Drawing Archaeological Finds. New York: Association Press, 1971

- CARMONA, J. D. (ed.) (2017) Schema. Revista de la Asociación Nacional de Dibujantes e llustradores de Arqueología, n. ${ }^{\circ} 1$

- CARmonA, J. D. (ed.) (2018) Schema. Revista de la Asociación Nacional de Dibujantes e llustradores de Arqueología, n. ${ }^{\circ} 2$

- DE LUIS, I.; MERRONY, C. (2010) Dibujo de campo y topografía para arqueólogos. Milán: EDAR Arqueología y Patrimonio-Hugony Editore, 2010 (Colección Estudios)

- DILON, B. D. (ed.) (1981) The Student's Guide to Archaeological Illustrating. California: Institute of Archaeology Press, University of California, 1981 (Serie Archaeological Research Tools, 1)

- HAWKER, J. (2001) A Manual of Archaeological Field Drawing. Hertford: Rescue,The British Archaeological Trust, 2001

- MAS, P. (2016) Dibujo arqueológico de materiales. Aproximación a sus técnicas. Palma, Illes Balears: Vessants Editores, 2016

- PENNACCHIONI, M. (2004) Metodologie e tecniche del disegno archeologico. Manuale per il disegno dei reperti archeologici. Firenze: All'Insegna del Giglio, 2004 (Serie Futuro Anteriore)

- PROSKOURIAKOFF, T. (1946) An Album of Maya Architecture. Notes on Middle American Archaeology and Ethnology, 3, 1946, pp. 143-150

- SEVILlano, M. A. (2013) Proyecto Asturica Emerge. En CENTENO DEL CANTO, P. (coord.) Actas de las 6as. Jornadas de Museología. Propuestas para financiar Museos y Colecciones [en línea]. León: Fundación Sierra Pambley, 2013, pp. $\quad 79-91<$ <ttps://museosp.files.wordpress.com/2014/07/ actas-museo-sierra-pambley-20131.pdf> 21/05/2019]

[Consulta:

- RUIZ, G. (2018) El Poder del Pasado. 150 años de arqueología en España. Madrid: Editorial Palacios y Museos. Ministerio de Cultura y Deporte, 2018 